\title{
Comparison of the Effects of Hypericum perforatum extract and its Microemulsion with Aloe vera Extract on Brucella melitensis
}

\author{
Mahsa Tabibnejad1, Mohammad Arjomandzadegan², Mohammad Yousef Alikhani ${ }^{3}$, \\ Maryam Sadrnia ${ }^{4, *}$, Ghasem Habibi ${ }^{5}$, Zahra Naseri ${ }^{6}$ \\ ${ }^{I}$ MSc in Microbiology, Infectious Diseases Research Center, Arak University of Medical Sciences, Arak, Iran \\ ${ }^{2}$ Associate Professor of Microbiology, Infectious Diseases Research Center, Arak University of Medical Sciences, Arak, Iran \\ ${ }^{3}$ Professor of Microbiology, Brucellosis Research Center, Hamedan University of Medical Sciences, Hamedan, Iran \\ ${ }^{4}$ Assistant Professor, Department of Biology, Payame Noor University, Iran \\ ${ }^{5}$ Medical Student, Infectious Diseases Research Center, Arak University of Medical Sciences, Arak, Iran \\ ${ }^{6}$ MSc in Microbiology, Blood Transfusion Research Center, High Institute for Research and Education in Transfusion, \\ Hamadan, Iran
}

* Corresponding Author: Maryam Sadrnia, Department of Biology, Payame Noor University, Iran. Email: msadrnia@yahoo.com

Received: 19.08 .2017

Accepted: 15.01 .2018

\section{How to Cite this Article:}

Tabibnejad M, Arjomandzadegan

M, Alikhani MY, Sadrnia M,

Habibi G, Naseri Z. Comparison of the Effects of Hypericum perforatum extract and its Microemulsion with Aloe vera Extract on Brucella melitensis. Avicenna J Clin Med. 2018; 24(4): 336-344. DOI: $10.21859 / \mathrm{ajcm}$ 24.4.336.

\section{Abstract}

Background and Objective: Today, due to the occurrence of drug resistance and the ability of bacteria to develop acute infections, investigating the antimicrobial effects of herbs has been proposed. Therefore, we aimed to examine the effects of Hypericum perforatum extract and microemulsion and Aloe vera extract on Brucella bacteria.

Materials and Methods: This experimental study was carried out with the help of a hood in a biosafety level 2 laboratory. Fifty blood serum samples were cultured in BACTEC for brucellosis, and if grown, they were transferred to Brucella Agar in an anaerojar containing $10-5 \% \mathrm{CO}_{2}$ for 48 $72 \mathrm{~h}$. Biochemical validation tests were carried out on the grown samples. Extraction was performed by a reflux (distillation) apparatus in a 1 liter balloon and a $40 \mathrm{~cm}$ spiral arm. Microemulsion structure was prepared by emulsifiers from the extract. Afterwards, 1, 8.4, and $2 \mathrm{mg} / \mathrm{L}$ dilutions of the aqueous extracts of Hypericum perforatum and Aloe vera were prepared, and the antimicrobial properties of these extracts were evaluated by disc diffusion, pour plate, and extraction methods on pure culture of Brucella isolated from patients.

Results: Evaluation of antimicrobial effects on the isolated Brucella strains showed that the mean diameters of the zones of inhibition in the studied strains for the of 8-1 mg/l concentrations of Hypericum perforatum extract were $36.6 \pm 2$ and $18 \pm 3 \mathrm{~mm}$, respectively, and for Aloe vera they were respectively $30.7 \pm 3$ and $18 \pm 1 \mathrm{~mm}$. None of the strains formed an inhibition zone at the $0.5 \mathrm{mg} / \mathrm{l}$ concentration. Evaluation of the effect of the extract in the well diffusion method also yielded similar results, but in the pour plate method, the effect of the extractes on the bacteria was not observed. Micoemulsion of the Hypericum perforatum extract did not have any effect because of over dilution.

Conclusion: The disk diffusion method under biosafety level 2 laboratory was highly effective, and the extract of Hypericum perforatum had the highest effect on Brucella; therefore, it is recommended for clinical studies.

Keywords: Aloe vera, Brucella, Brucellosis, Hypericum perforatum, Microemulsion 


\title{
مقايسه اثر عصاره تل راعى و ميكروامولسيون آن با عصاره آلوئه ورا بر باكترى بروسلك
}

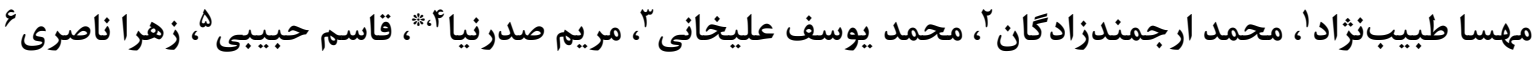

' كارشناسى ارشد ميكروبشناسى، مركز تحقيقات بيمارىهاى عفونى، دانشكاه علوم يزشكى اراك، اراك، ايران

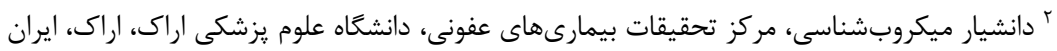

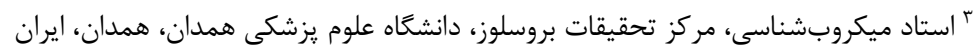

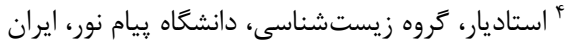

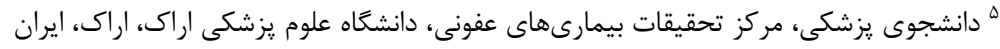

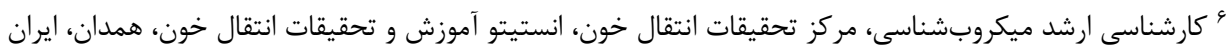

* نويسنده مسئول: مريم صدرنيا، گروه زيستشناسى، دانشگاه يِام نور، ايران. ايميل:yahoo.com

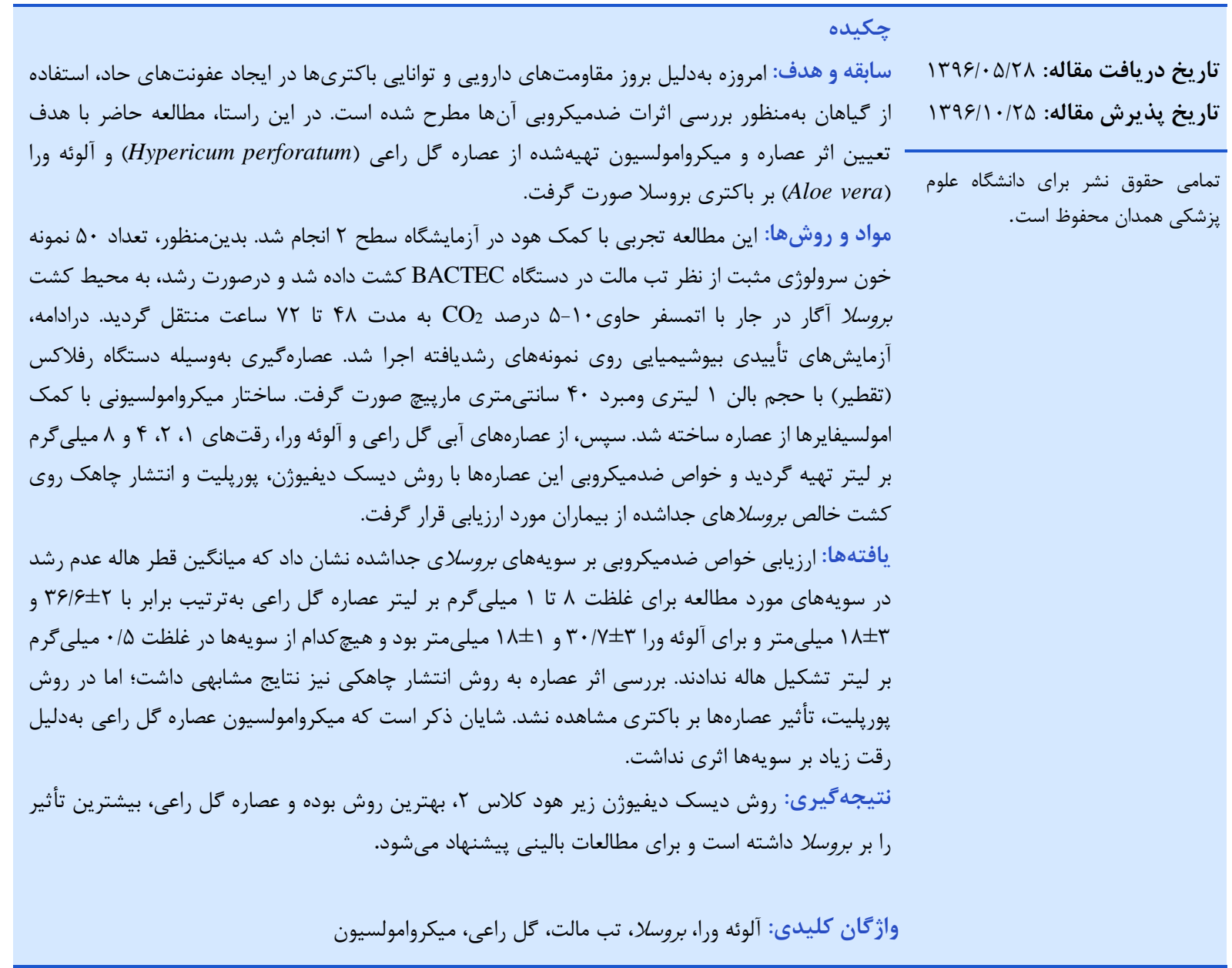

نئوتوم (neotomae) تقسيمبندى شده است [r]

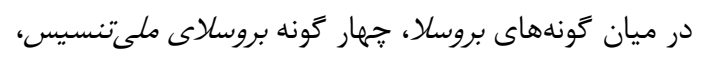

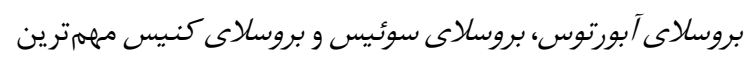

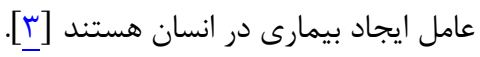

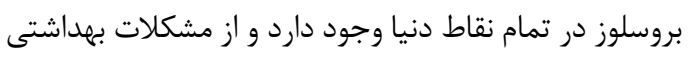

بروسلا (Brucella)، باكترى كوكوباسيل گرم منفى بدون

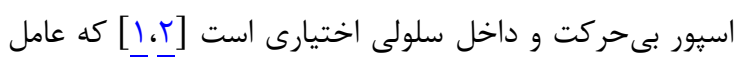

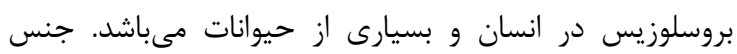

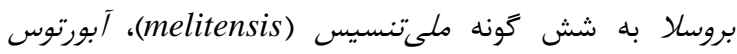
(abortus)، سوئيس (suis)، اويس (ovis)، كانيس (canis) و و 
كَياه دارويى بلويزه براى درمان افسردگى ملايم تا متوسط بلطور

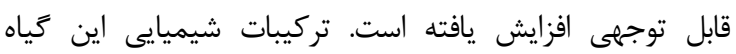

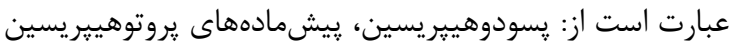

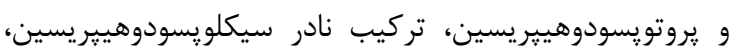
فلاونوئيدهايى نظير كاميفرول، كوئرستين، هييروزيد، ايزو كوئرستين،

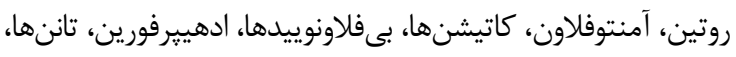
كافئيك، كلروزنيك و روغنهاى فرار مانند زرانيول، ميرسن، ليمونن، هيوميولن، كاريوفيلن، ميريستيك، يالمتيك، استئاريك، كارتنوئيدها،

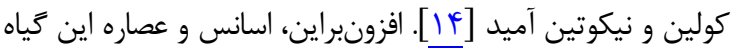

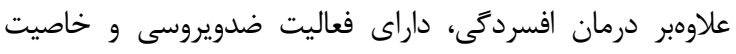

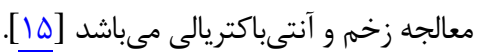
درمجموع هدف از مطالعه حاضر، تعيين اثر عصاره كياه كل

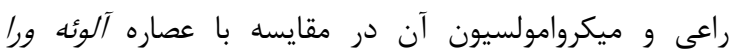
بر باكترى مولد تب مالت در شرايط برونتنى مى داشد.

\section{مواد و روشها جداسازى باكترى}

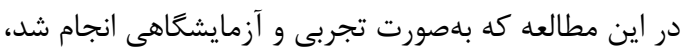

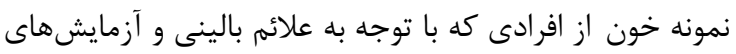

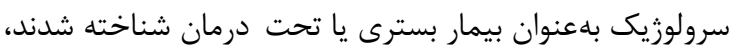

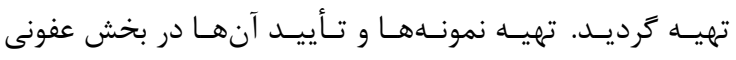

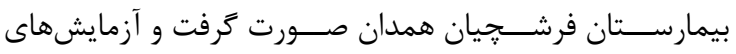

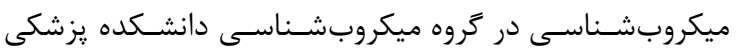

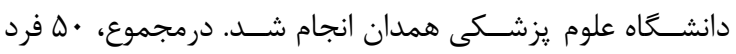

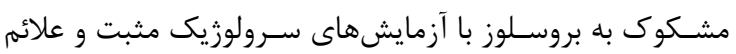

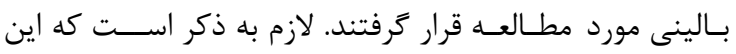

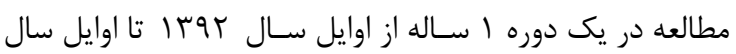

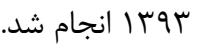

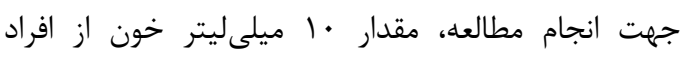

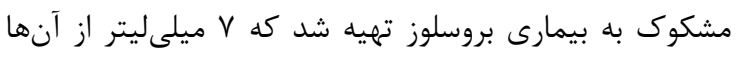
براى كشت در محيطهاى BACTEC استفاده شد. ويالهاى

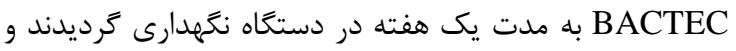
موارد مثبت به محيطهاى كشت بروسلا آكار (Brucella agar)

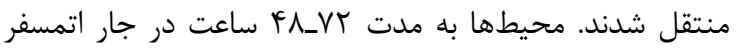
حاوى • •-ه درصد نكَهدارى گرديدند. ذكر اين نكته ضرورت دارد كه تمام محيطهاى

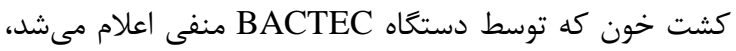

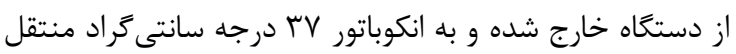

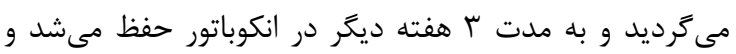

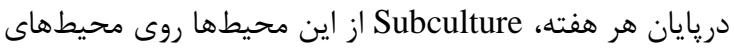

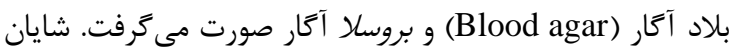

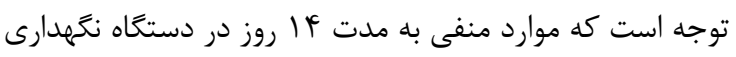

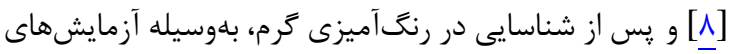
اكسيداز، اورهآز، كاتالاز و توليد كاز
در بسيارى از كشورها محسوب مىشود. اين بيمارى در بسيارى

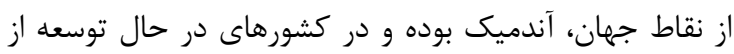

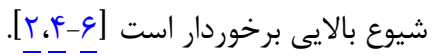

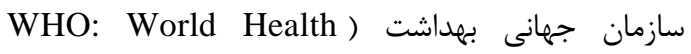
تعداد موارد جديد بيمارى بروسلوز در هر سال (Organization

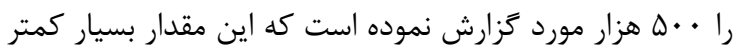

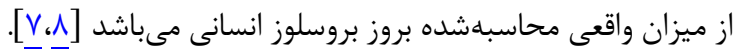

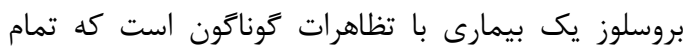

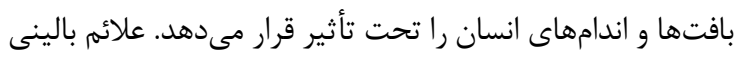

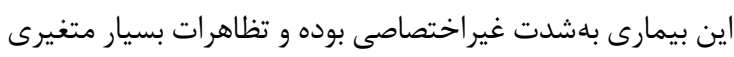

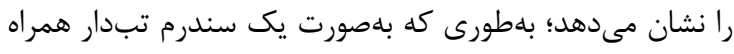

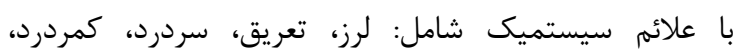

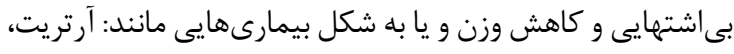

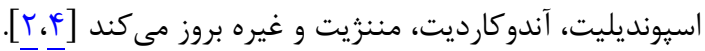

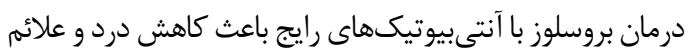

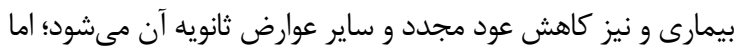

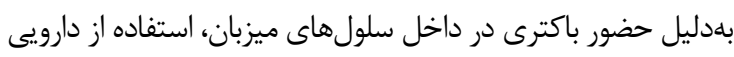

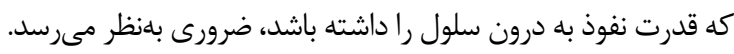

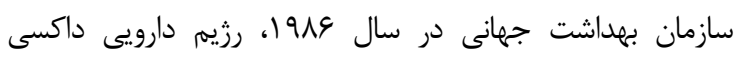

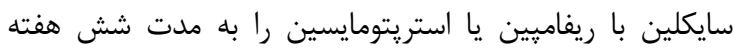

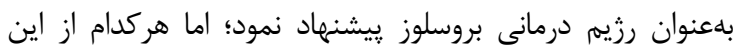

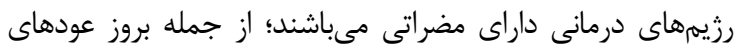

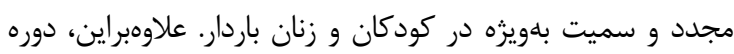

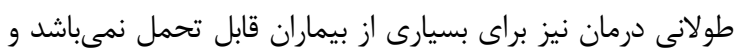

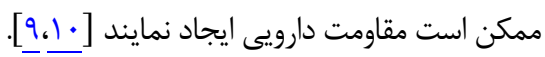

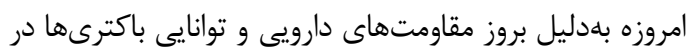

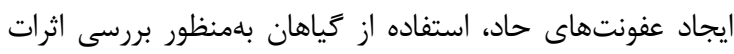

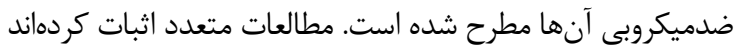

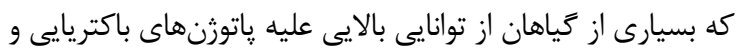

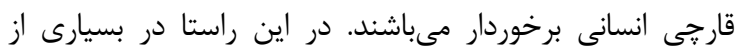

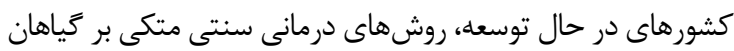

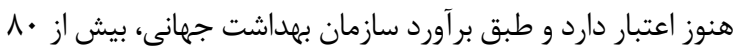

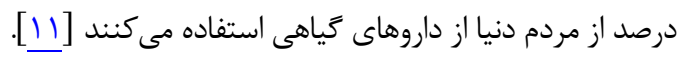

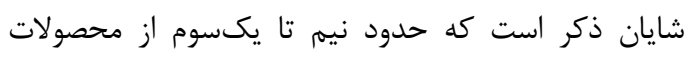

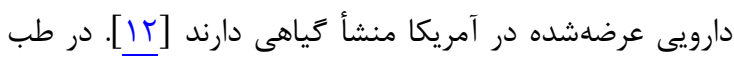

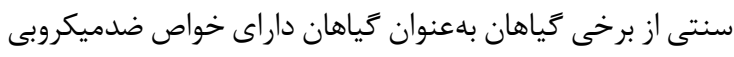

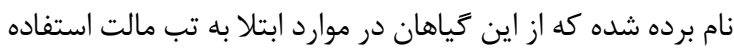

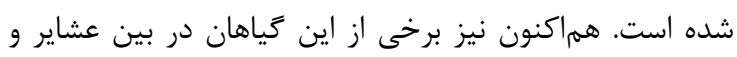

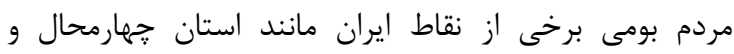

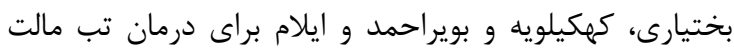

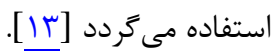
گل راعى با نام علمى Hypericum perforatum يك گياه علفى از خانواده Hypericaceae است كه بومى غرب ارئ ارويا، آسيا و شمال آفريقا مىباشد. كاربرد اين گياه در جند سال اخير بهعنوان 
معادل رقت نيم مكفارلند كشت جمنى گسترده انجام شد.

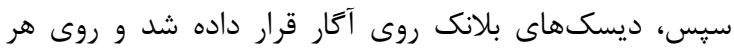

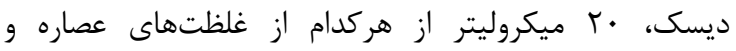

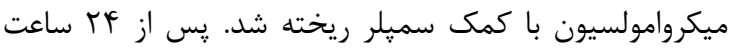

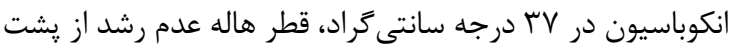
يليت با خط كش ميلىمترى اندازهزيرى گرديد.

\section{روش يوريليت}

مقدار ه • • سىسى از هركدام از رقتهاى عصاره و

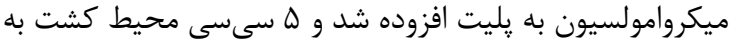

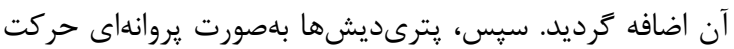

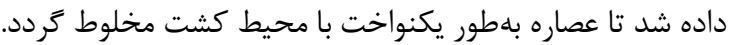

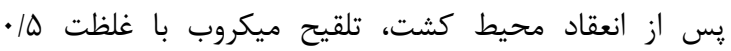
مكفارلند و با استفاده از سواب انجام شد.

روش انتشار קاهك

جاهكهايى با قطر ه ميلىمتر روى محيط بروسلا آكار ايجاد

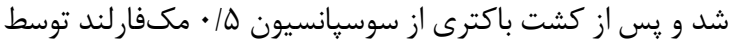

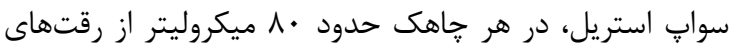

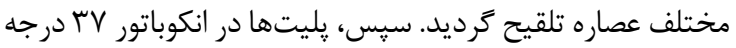

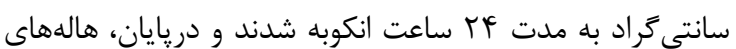
عدم رشد باكترىها توسط خط كش اندازهَيرى گرديد. درنهايت در نمونه شاهد، ميكروب روى محيط كشت بروسالا آتار فاقد جاهك و عصاره كشت داده شد.

بافته ها

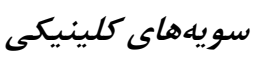

كشت خون در مورد • له فرد مشكوك به بروسلوز كه از نظر

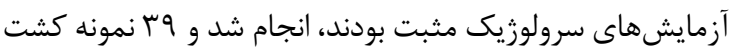

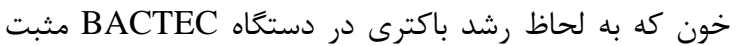
بودند، روى بروسلا آحار برده شدند.

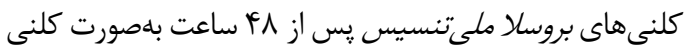

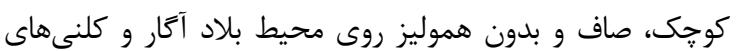

كوجى و صاف روى محيط بروسلا آكار رشد يافتند [IV،IN]

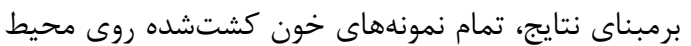

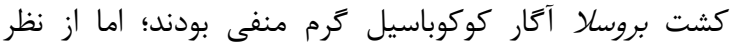

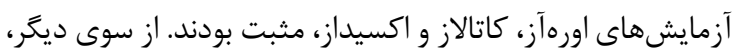

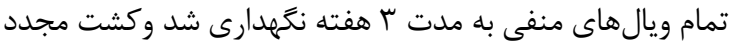
صورت گرفت كه نتيجه تمامى آنها منفى بود.

\section{نتا يج ديسك ديفيوزن}

نتايج نشان داد كه حداكثر و حداقل هاله عدم رشد براى

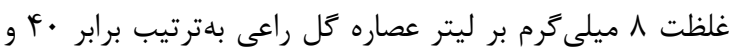
اس ميلىمتر در باكترى بروسلا مىباشد؛ بهطورى كه در نمونه
تههيه كياه

دو گياه گل راعى و آلوئه ورا بلهصورت تازه از مزرعه گياهان

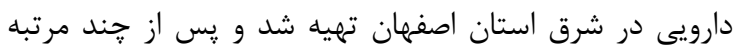

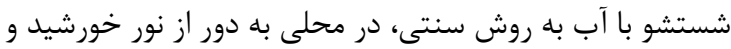

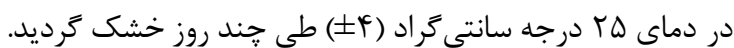

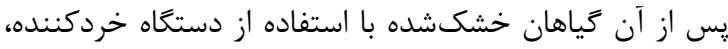

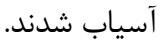

تهيه عصاره /ز آلوئه ورا و تحل راعى

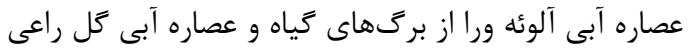

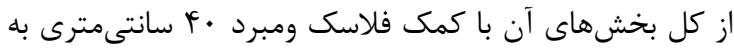
روش رفلاكس تهيه گرديد.

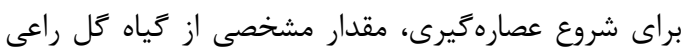

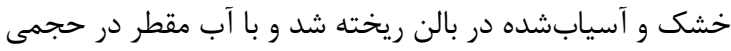

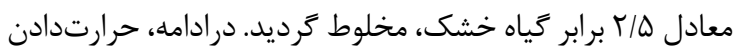
به مدت 9 ساعت در بنمارى در دماى جوش انجام شد؛

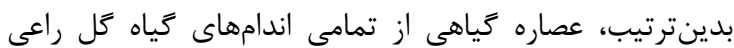
بهدست آمد. براى صافكردن عصارهها و جداسازى مواد معلق ناخالص نيز از سانتريفيوز استفاده گرديد [عادئ.

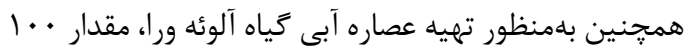

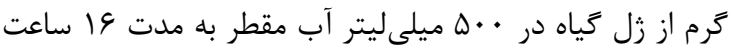

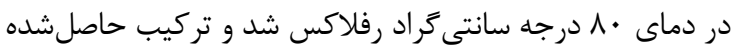
در بالن تقطير يس از سردكردن، صاف شده و و بهعنوان عردان عصاره كَياهى مورد استفاده قرار كرفت.

\section{نوليد ميكروامولسيون از عصاره Fل راعى}

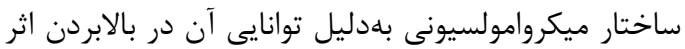

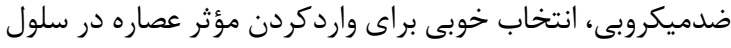

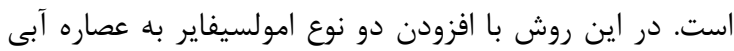

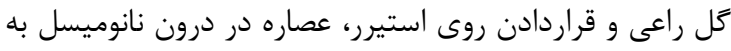

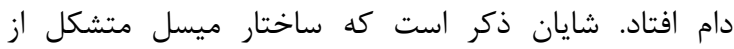
فسفوليييد بوده و بهصورت كروى به قطر تقريبى ه تا • لـ نانومتر مى باشد.

تهييه رقت از عصارهها

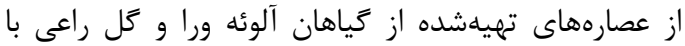

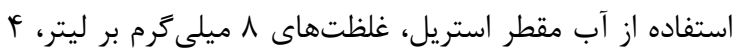
ميلى گرم بر ليتر، † ميلى گرم بر ليتر، ا ميلى

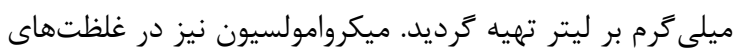

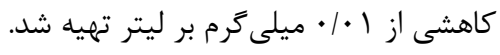

روش ديسك ديفيوزن

روى محيط كشت مولر هينتون آكار (Mueller hinton agar)

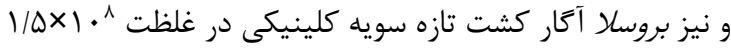


ه، צب و و 1 ميلىمتر نشان داده شد. علاوهبراين، تمامى نمونهها

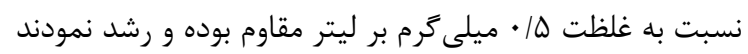

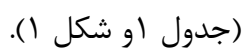

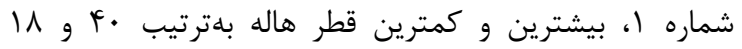

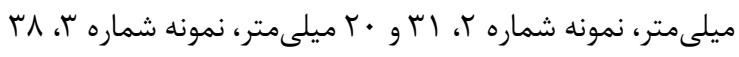

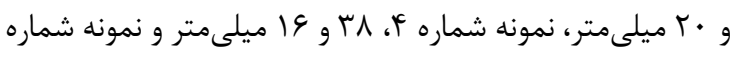

جدول ا: نتايج قطر هاله حاصل از تأثير رقتهاى مختلف عصاره گل راعى (ميلى

\begin{tabular}{|c|c|c|c|c|c|}
\hline$\cdot / \Delta$ & 1 & غت & p & $\wedge$ & شماره نمونه \\
\hline عدم وجود هاله & 11 & $r \Delta$ & rV & f. & 1 \\
\hline عدم وجود هاله & $r$. & $r \Delta$ & $r \omega$ & m & r \\
\hline عدم وجود هاله & $r$. & $r \Delta$ & זr & ऍ^ & r \\
\hline عدم وجود هاله & 19 & TA & Mr & ץᄉ & r \\
\hline عدم وجود هاله & 19 & re & rq & re & $\Delta$ \\
\hline
\end{tabular}

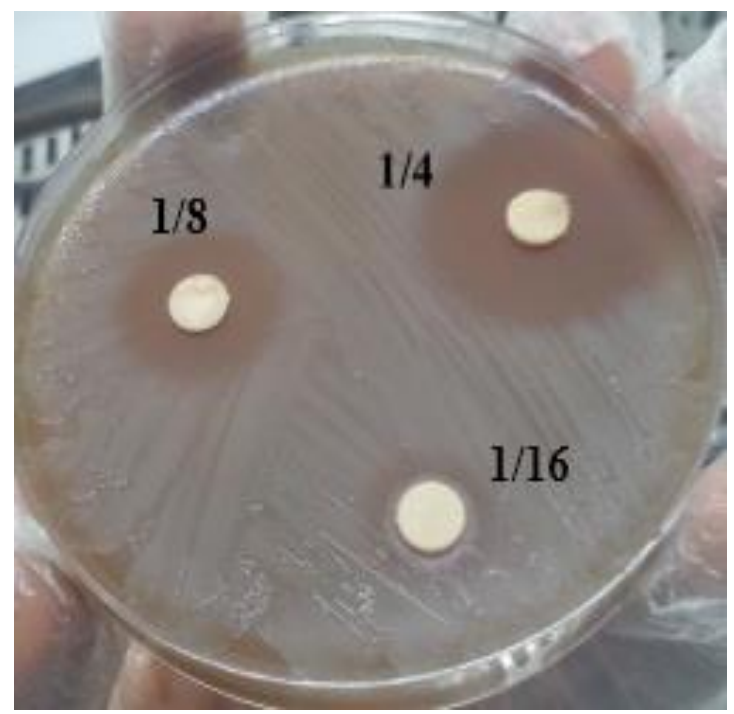

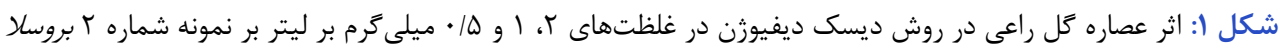

ميلى گرم بر ليتر براى نمونه شماره ب به اندازه Vا ميلى متر است

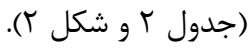

\section{نتايج يوريليت}

يس از كشت باكترى روى محيط كشت حاوى رقتهاى

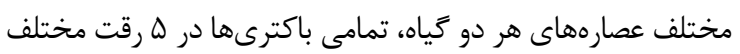

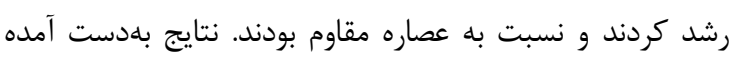

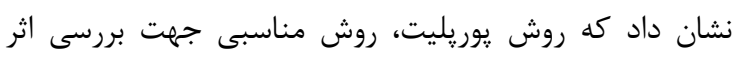

نتا يج انتشار جاهكى

در جدول r، قطر هالههاى عدم رشد براى هائ سويه بروسلا

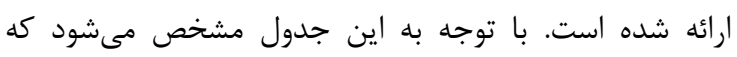
بيشترين قطر هاله عدم رشد مربوط به رقت 1 ميلى

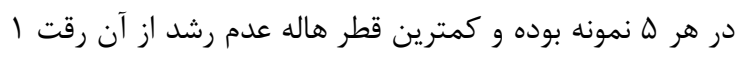
ميلى

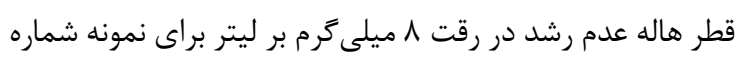

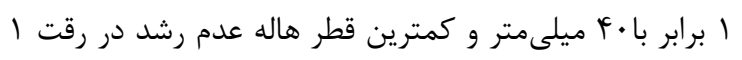

جدول ץ: نتايج حاصل از بررسى تأثير رقتهاى مختلف عصاره گل راعى (ميلى

\begin{tabular}{|c|c|c|c|c|c|}
\hline$\cdot / \Delta$ & 1 & قت = & $p$ & $\Lambda$ & شماره نمونه \\
\hline عدم وجود هاله & rI & rA & ra & $f$. & 1 \\
\hline عدم وجود هاله & $r \cdot$ & זr & rA & rI & r \\
\hline عدم وجود هاله & IV & TQ & rt & rV & r \\
\hline عدم وجود هاله & 11 & rA & ry & rی & f \\
\hline عدم وجود هاله & 11 & TQ & rq & rq & $\Delta$ \\
\hline
\end{tabular}




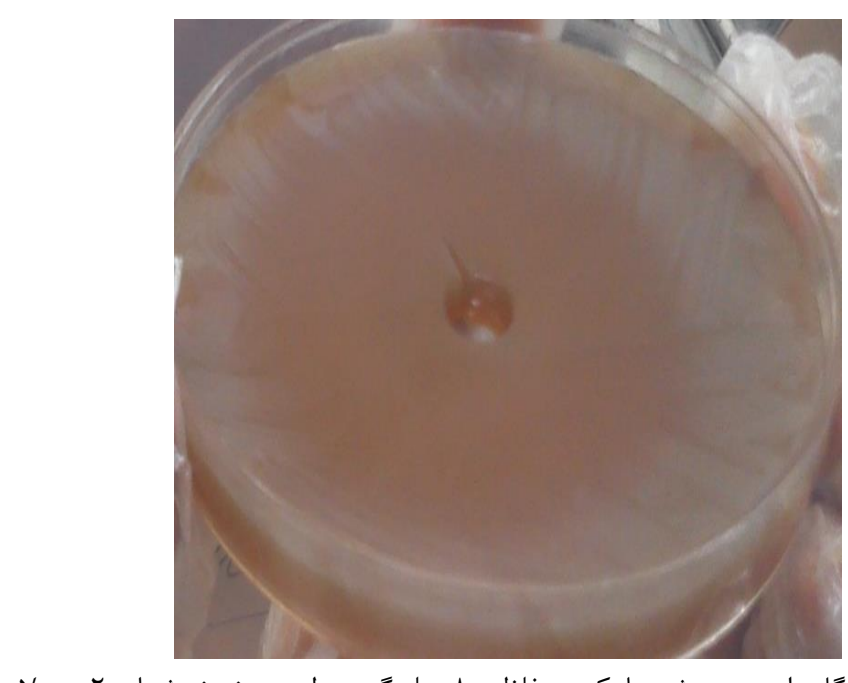

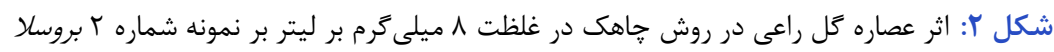

\section{نتا يج ديسك ديفيوزن}

عصاره نمى باشد.

حداكثر هاله عدم رشد براى عصاره آلوئه ورا در غلظت 1 دئي

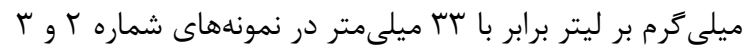

نتايج بررسى اثر ميكروامولسيون توليدشده /ز عصاره تل

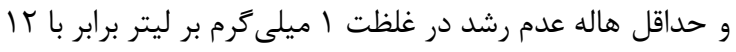

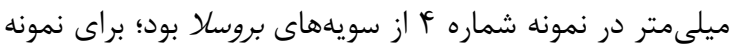

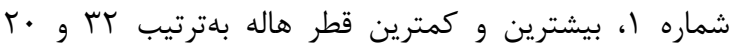

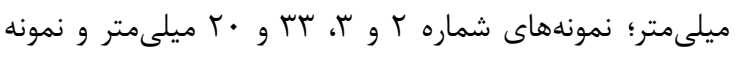

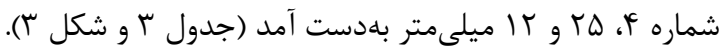
فمعاليت جدول ب: نتايج حاصل از بررسى اثر رقتهاى مختلف عصاره آلوئه ورا (ميلى

\begin{tabular}{|c|c|c|c|c|}
\hline 1 & $r$ & $f$ & $\wedge$ & شماره نمونه \\
\hline$r$. & rd & 「^ & Tr & 1 \\
\hline$r$. & rd & TV & זr & $r$ \\
\hline$r$. & $r \Delta$ & $r$. & זr & $r$ \\
\hline IT & 11 & rז & $r \omega$ & r \\
\hline
\end{tabular}

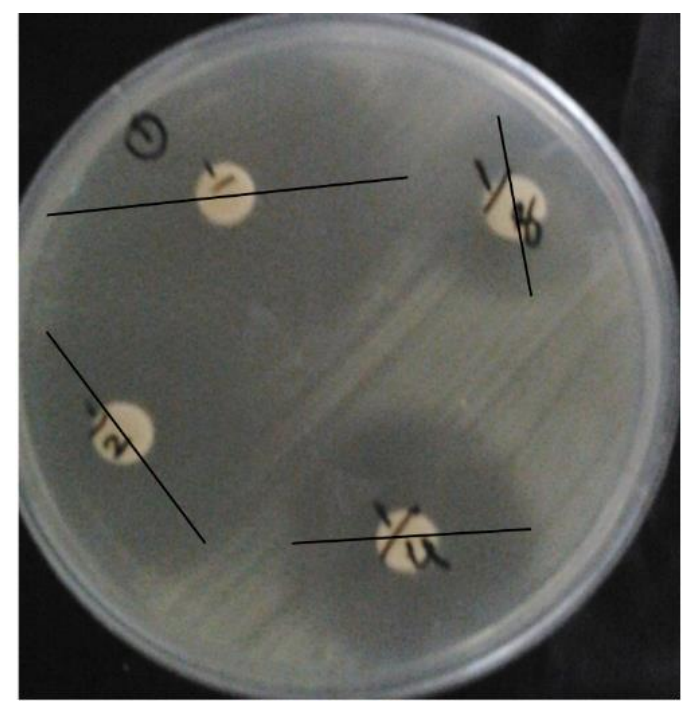

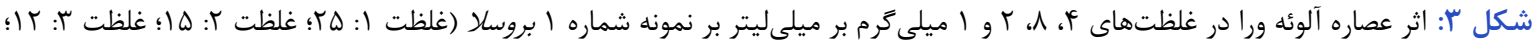

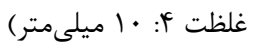


و از رشد باكترى ممانعت كرده است [19]. بايد عنوان نمود كه يافتههاى اين مطالعه با نتايج بهدست آمده از مطالعه حاضر باند مطابقت داشت.

عنايتزاده ميمندى و همكاران نيز در مطالعهاى نشان دادند

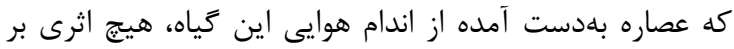

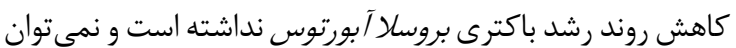

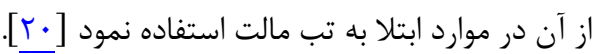

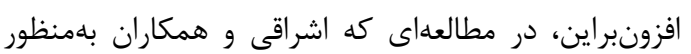

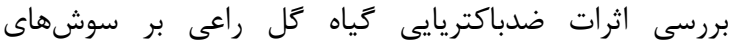
بيمارىزاى نوكارديا (Nocardia) انجام داد، زَزارش شد شد كه

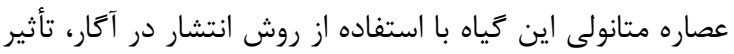

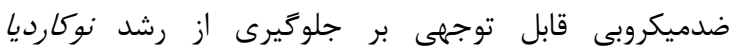
استروئيد (Nocardia asteroides) و نوكيكروبى (Nocardia brasiliensis)

(Nocardia brasiliensis) برخى از گونههاى گل راعى در طب سنتى بلهعنوان داروى

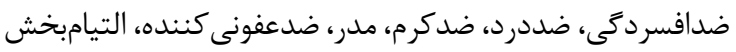

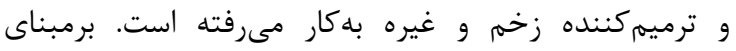

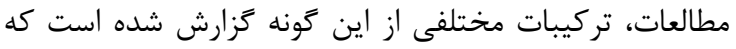

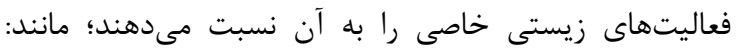

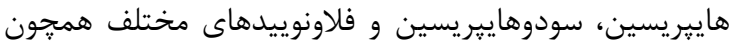

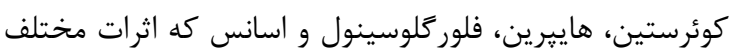

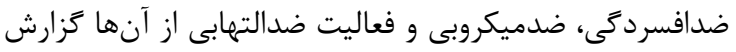

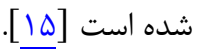
نتايج بررسى ضدباكتر يايى در مطالعه حاضر نشاندهنده تأثير

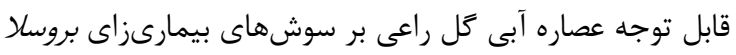

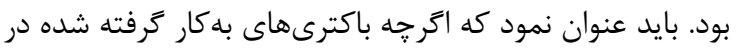

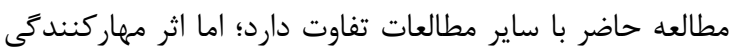

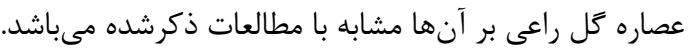

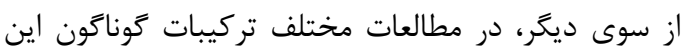

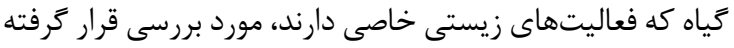

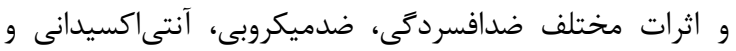

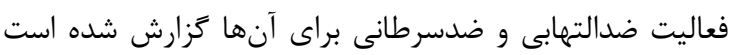

[rt-rt]

در اين راستا، نتايج مطالعهاى مشخص كرد كه اقوام بومى

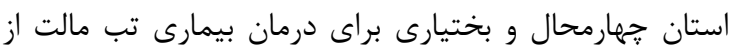

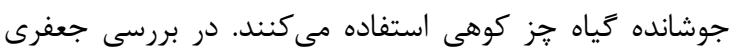

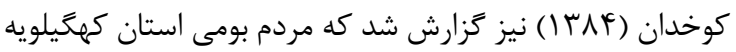

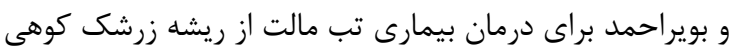
(Berberis vulgaris) همجنين، در مطالعه ديخرى به بررسى اثر عصاره كلروفرمى

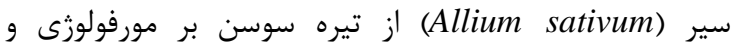
فيزيولوزى بروسلا يرداخته شد. طى اين مطالعه مشخص ترديد

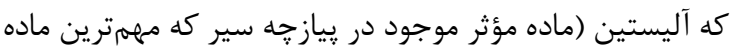

در اين مطالعه اثرات سه ماده عصاره گل راعى، ميكروامولسيون

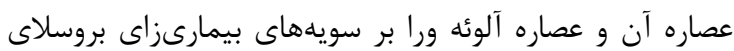

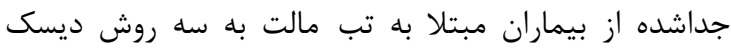

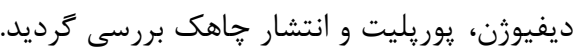

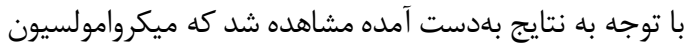
عصاره گل راعى، اثر مهارى بر رشد سويلهاى بروسلا ندارد. نكته بهائ

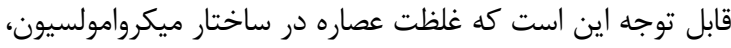

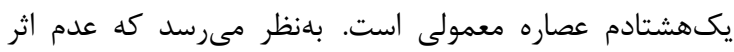

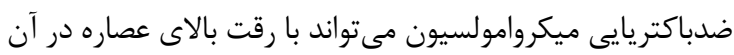
و نيز غلظت پايين مواد مؤثر مرتبط باشد. در روش ديسك ديفيوزن، نتايج متفاوتى از نظر هاله عدم

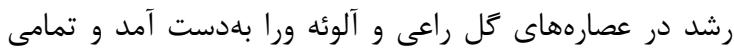

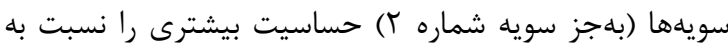

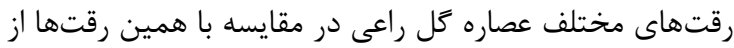

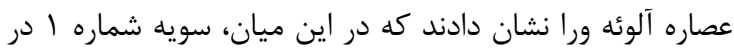

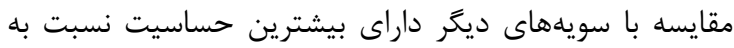
رقتهاى مختلف عصاره گل راعى بود.

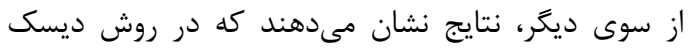

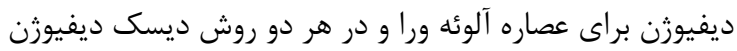

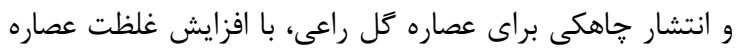

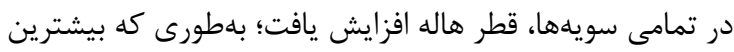
قطر در غلظت ^ ميلى

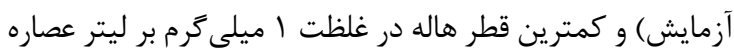

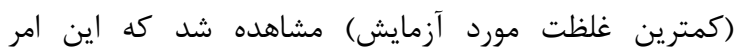

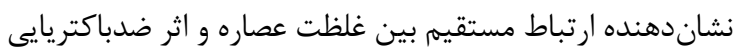

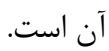

علاوهبراين، در مطالعه حاضر عصاره گياه گل راعى با روش

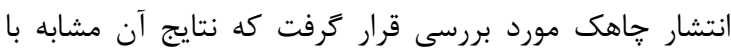
يافته هاى حاصل از روش ديسك ديفيوزن بود.

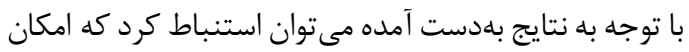

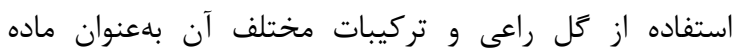

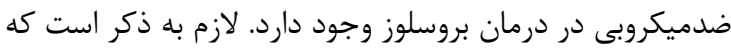

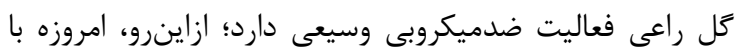

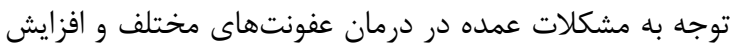

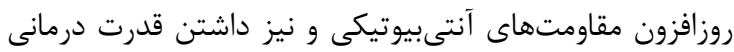

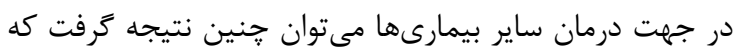

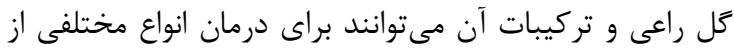
بيمارى ها به كار ترفته شوند. در اين زمينه، در مطالعهاى كه شايورى و همكاران بلهمنظور

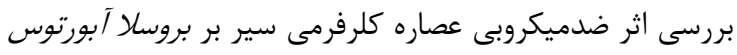

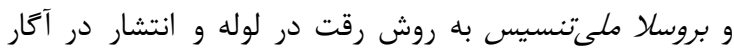

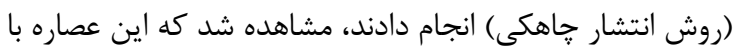

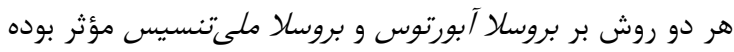


مطالعه حاضر بروسلا بهعنوان يك باكترى گرم منفى بيمارىزا

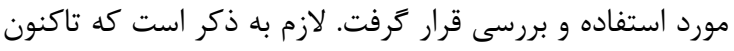

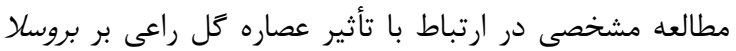
صورت نخرفته است و بلنظر مىرسد كه مطالعه حاضر در نوع

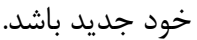

\section{نتيجه تيرى}

در مطالعه حاضر مشاهده شد كه عصاره گل راعى و آلوئه ورا

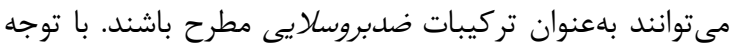
به اثرات آنتىاكسيدانى و تقويت كنندهگى سيستم ايمنى اين

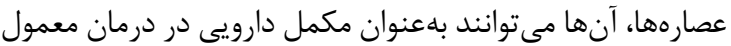

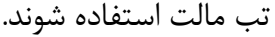

$$
\text { تشكر و قنر داذى }
$$

اين مقاله حاصل از طرحى يزوهشى مى باشد كه با همكارى

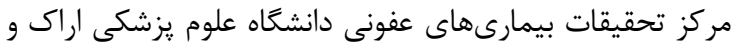

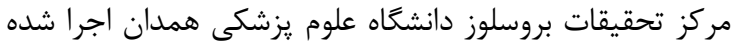

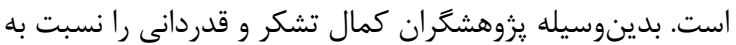

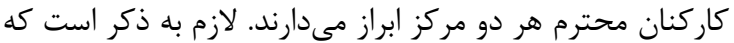

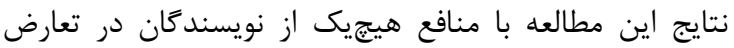
نمى باشد.

\section{REFERENCES}

1. Hosseini-Doust SR, Ahmadi A, Ahmadi Z, Hajia M, Safiri Z, Golmanesh L. Detection of brucella abortus by PCR assay and comparison with culture assay. $J$ Mil Med. 2005;7(3):239-44. [Persian]

2. Pishva A, Salehi M, Ebrahimi M, Salehi R. Identification of brucella spp in central region of Iran. Iran J Biol. 2007;20(1):15-21. [Persian]

3. Zhouqi A, Samar G. Interpretation of brucellosis quick experiments. J Nabz. 1996;6:26-30. [Persian]

4. Haji Khani B, Sepehri Serasht S. Senior Microbiology. Tehran: Ibn Sina University Jihad; 2010.

5. Al-Eissa YA. Brucellosis in Saudi Arabia: past, present and future. Ann Saudi Med. 1999;19(5):403-5. PMID: 17277503

6. Bailey W, Scott EG. Diagnostic microbiology. $10^{\text {th }}$ ed. New York: Elsevier Health Sciences; 1998.

7. Rezazadeh M, Hajilooi M, Rafiei A, Haidari M, Nikoopour E, Kerammat F, et al. TLR4 polymorphism in Iranian patiants with brucellosis. J Infect. 2006;53(3):206-10. Doi: 10.1016/j. jinf.2005.10.018

8. Maleknejad P, Peeri-Dogaheh H, AmirZargar AA, Jafari S, Fatollahzadeh B. Diagnosis of brucellosis by use of BACTEC blood culture and confirmation by PCR. $J$ Vet Res. 2007;62(4):83-6.

9. Morata P, Queipo-Ortuno MI, Reguera JM, Garcia-Ordonez MA, Cardenas A, Colmenero JD. Development and evaluation of a PCR-enzym-linked immunosorbent assay for diagnosis of human brucellosis. J Clin Microbiol. 2003;41(1):144-8. PMID: 12517839

10. Martínez de Tejada G, Pizarro-Cerdá J, Moreno E, Moriyon I. The outer membranes of brucella spp. are resistant to bactericidal cationic peptides. Infect Immun. 1995;63(8):3054-61. PMID: 7622230

11. Serrentino J. How natural remedies work. New York: Harley and Marks Publishers; 1991. P. 20-2.

12. Clark AM. Natural products as a resource fornew drugs. Pharm Res. 1996;13(8):1133-44. PMID: 8865302

13. Pirbalouti AG. Medicinal plants used in Chaharmahal and Bakhtyari districts of Iran. Herba Polonica. 2009;55(2):
ضدعفونى كننده سير است) اثر ممانعتكننده مؤثرى بر رشد باكترى بروسلا در شرايط In-vitro داشته است. همجنين نشان

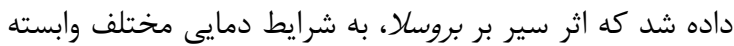
نبوده و اثر كشندگى خود را در همان دو ساعت اول بر باكترى

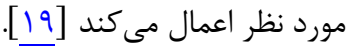
علاوهبراين، طى مطالعهاى كه در ارتباط با تأثير جند جند كياه

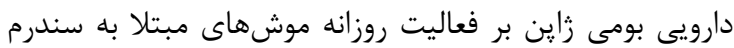

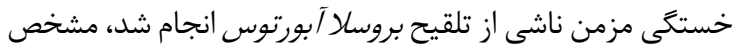

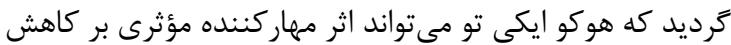
فعاليت روزانه داشته باشد [عرديد. ذكر اين نكته ضرورت دارد كه مطالعات بسيارى در ارتباط با باله

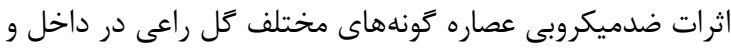
خارج از كشور صورت گرفته است. در مطالعات انجامشده در كشور ايران، بيشتر به بررسى اثرات ضدافسردگى، ضدالتهابى،

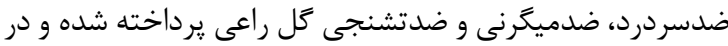

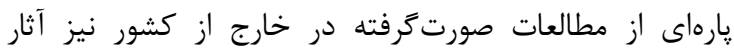

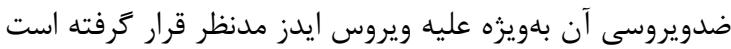
$[r V-r q]$

با توجه به اينكه مطالعات انجامشده در داخل و خارج از كشور

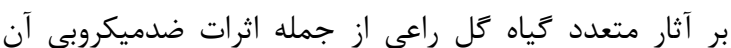

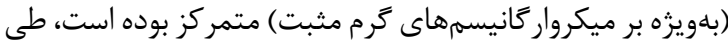

$669-75$

14. Mirza M. Research of medicinal and aromatic plants. New York: Publications of Forests and Meadows;1998. P. 1.

15. Naghdi Badi H, Amin G, Makkizadeh M, Ziai SA. St. John's wort (Hypericum perforatum L.): a review. J Med Plants. 2005;4(16):1-4. [Persian]

16. Barnes J, Anderson A. Phillipson JD. St. John's wort (Hypericum perforatum L.): a review of its chemistry, pharmacology and clinical properties. J Pharm Pharmacol. 2001;53(5):583-600. PMID: 11370698

17. Yagupsky P. Detection of Brucellosis in blood cultures. $J$ Clin Microbiol. 1999;37(11):3437-42. PMID: 10523530

18. Bannatyne RM, Jackson MC, Memish Z. Rapid diagnosis of Brucella bacteremia by using the BACTEC 9240 system. $J$ Clin Microbiol. 1997;35(10):2673-4. PMID: 9316932

19. Shapoury R, Sattari M, Mohammad Hassan Z. Study effect of garlic choloroformic extract (Allicin) on physiology and morphology of brucella. J Med Plants. 2004;2(10):15-22. [Persian]

20. Anayatzade Meimandi SA. Effect of Teucrium spp. And local name (Chez Kouhi) on Brucella abortus bacteria. [Master Thesis]. Shahrekord: Islamic Azad University, Shahrekord Branch; 2005. [Persian]

21. Eshraghi S, Amin G, Othari A. Evaluation of antibacterial properties and review of 10 medicinal herbs on preventing the growth of pathogenic nocardia species. J Med Plants. 2009;88(32):60-78. [Persian]

22. Cecchini C, Cresci A, Coman MM, Ricciutelli M, Sagratini G, Vittori S, et al. Antimicrobial activity of seven Hypericum entities from central Italy. Planta Med. 2007;73(6):564-6. PMID: 17516331 DOI: 10.1055/s-2007-967198

23. Kang BY, Chung SW, Kim TS. Inhibition of interleukin-12 production in lipopolysaccharide-activated mouse macrophages by hpyericin, an active component of Hypericum perforatum. Planta Med. 2001;67(4):364-6. PMID: 11458458 DOI: $10.1055 / \mathrm{s}-2001-14333$

24. Gartner M, Muller T, Simon JC, Giannis A, sleeman JP. Aristoforin, a novel stable derivative of hyperforin is a potent 
anticancer agent. Chembiochem. 2005;6(1):171-7. PMID: 15593112 DOI: $10.1002 /$ cbic. 200400195

25. Jafari Kookhdan AS. Traditional medicine in the great Qashqai. Proceedings of the National Conference on the Sustainable Development of Medicinal Plants, Mashhad, Iran; 2005. P. 647.

26. Xing, QW, Takashi T, Zhu SJ, Moriya J, Saegusa S, Yamakawa J, et al. Effect of Hochu-ekki-to (TJ-41), a Japanese Herbal Medicine, on daily activity in murine model of chonic fatigue syndrome. Evid Based Complement Alternat Med. 2004;1(2):203-6. PMID: 15480446 DOI: 10.1093/ecam/neh020
27. Länger R. Die HMPC-Monographie zu Hypericum: Hintergründe, Entstehung, Inhalte. WMW Wiener Med Wochenschrift. 2010;160(21):557-63. DOI 10.1007/s10354010-0846-6

28. Isacchi B, Bergonzi MC, Carnevali F, van der Esch SA, Vincieri FF, Bilia AR. Analysis and stability of the constituents of St. John's wort oils prepared with different methods. J Pharm Biomed Anal. 2007;45(5):756-61. PMID: 17920801 DOI: $10.1016 /$ j.jpba.2007.08.025

29. German pharmacopoeia, EB6 (Deutsches Arzneibuch. Suppl.). $6^{\text {th }}$ ed. Bonn: Phytopharmaceutical Corporation; 1941. P. 409. 